\title{
Connotations and Establishment Countermeasures of Yunnan High Education Radiation Center under "The Belt and Road" Initiatives
}

\author{
Zhang Honglie \\ Bangkok Business School \\ Yunnan University of Finance and Economics \\ Kunming, China \\ yufehelen@126.com
}

\begin{abstract}
To establish a radiation center opening-up to South and Southeast Asia is a new requirement and goal for future development in Yunnan province under "The Belt and Road" Initiatives and leadership of central government. Although there is no direct reference to education in the "The Belt and Road" Initiatives, to establish a radiation center opening-up to South and Southeast Asia which is strategic focus on "Paying special attention to Five Works" and "Playing on Six Cards", are all related to education. High education has played a significant, fundamental, overall and leading role in cultural exchanges and talent Cultivation and development. This paper proposed the construction suggestions and countermeasures by studying connotation characteristics of establishing a radiation center opening-up to South and Southeast Asia.
\end{abstract}

Keywords-Yunnan high education radiation center; connotation; establishment countermeasure

\section{INTRODUCTION}

When Chinese President Xi Jinping visited Central Asia and Southeast Asia in September and October of 2013, he raised the initiative of jointly building the Silk Road Economic Belt and the 21st-Century Maritime Silk Road (referred to as the Belt and Road), which have attracted close attention from all over the world. When General Secretary Xi Jinping visited Yunnan in January of 2015, he proposed: Yunnan should actively service and integrate into national development strategies, create a path by leapfrog development, strive to become the demonstration area of national unity and progress of our country, the vanguard of ecological civilization construction, the region a pivot of China's opening-up to South and Southeast Asia, compose the Yunnan chapter of the Chinese dreams.

\section{CONNOTATIONS OF YUNNAN High EdUCATION RADiATION CENTER}

Radiation originally is the concept of physics, such as propagation of light and heat, it refers to the battery energy emitted by the source part of Energy spread out in the form of electromagnetic waves or particles [1]. Some studies show that radiation center is the central region of human elements that formed the center point of convergence; the radiation effect is manifested as in the radiation area of divergence process.
Forming a radiation center is determined by the central region of the intrinsic cultural conditions [2]. The radiation center opening for South Asia, Southeast Asia was proposed by General Secretary $\mathrm{Xi}$ Jinping, was borrowed from the traditional concept of radiation, and giving a new meaning, its core is openness and cooperation, its purpose is mutual benefit and common development, advancing the construction of an international transport corridor connecting China with neighboring countries, developing a new highlight of economic cooperation in the Greater Mekong Sub region.

"Vision and proposed actions outlined on jointly building Silk Road Economic Belt and 21st-Century Maritime Silk Road" initiative issued by the National Development and Reform Commission, Ministry of Foreign Affairs, and Ministry of Commerce of the People's Republic of China, in March of 2015, which clearly stated Yunnan should make good use of the geographic advantage of Yunnan province, advance the construction of an international transport corridor connecting China with neighboring countries, develop a new highlight of economic cooperation in the Greater Mekong Subregion, and make the region a pivot of China's opening-up to South and Southeast Asia. Related scholars believed that the intension of making Yunnan a center pivot of China's opening-up to South and Southeast Asia is making good use of the geographic advantage and bringing together a wide range of domestic and foreign resources, Openness, development, cooperation, mutual benefit as their theme; policy coordination, facilities connectivity, unimpeded trade, financial integration and people-to-people bonds as their five key areas [3-7].

The general framework of "The Belt and Road" is five connections, namely facilities connectivity, unimpeded trade, financial integration, policy coordination and people-to-people bonds. Although there is no direct reference to education in "The Belt and Road" initiative, high education has played a significant, fundamental, overall and leading role in cultural exchanges and talent Cultivation and development. "Five connections" firstly is people-to-people bonds. In order to achieve that education should play a role in promoting mutual understanding, mutual trust, mutual respect and friendship between the peoples of the countries along the line. Talent promoting is the key to "The Belt and Road". There is an 
urgent need to train talents with international vision, master along the national foreign language, be familiar with the rules of international competition, and also along the country also need to be proficient in the Chinese language, familiar with China's economic and cultural strategy of internationalized talents.

Yunnan high education, as the Yunnan province and the South East Asian Education and cultural exchanges and personnel training base in Yunnan, should take the responsibility of the task of high education radiation center. The high education of Yunnan radiation center connotation is the combination of Yunnan location advantage, talent advantage, discipline construction and training mode and curriculum system construction, cultivating innovative talents for South Asia, "The Belt and Road" implementation of the strategy to cultivate talents proficient in Chinese and foreign countries along, familiar with international rules, the competition with international vision; along the country to attract more students to Yunnan to learn and exchange, In order to implement a good service to the "The Belt and Road" initiative, Yunnan high education should "go out" to carry out overseas education in South Asian countries, and promote the scientific research personnel training, cultural exchange, the Yunnan high education should become China's center for education cultural radiation in South Asia and Southeast Asian countries for its strong influence and radiation force and driving force.

\section{SIGNIFICANCE OF ESTABLISHING YUNNAN HIGH EDUCATION RADIATION CENTER}

Although there is no direct reference to education in "The Belt and Road" initiative, high education has played a significant, fundamental, overall and leading role in cultural exchanges and talent Cultivation and development. "Five connections" firstly is people-to-people bonds. In order to achieve that education should play a role in promoting mutual understanding, mutual trust, mutual respect and friendship between the peoples of the countries along the line. Establishing Yunnan high education radiation center pivot is an important part and measure of the opening up of Yunnan education, which in favor of making Yunnan a center pivot of China's opening-up to South and Southeast Asia. It is of great significance to further improve the level of opening up and promote economic development across the world.

\section{A. In Favor of Enhancing the Level of Internationalization of Yunnan High Education, Promoting the Opening of Yunnan Education}

Further accelerating the reform and expanding the opening is an important measure to readjust the structure, stabilize growth and promote balance in the new China. Education opening is an important part of China's reform and opening up, which undertaken to promote the implementation of innovation driven development strategy, developing the country through science and education strategy, talent strategy of the country's national mission. Making Yunnan high education a centre pivot is in favor of the innovation of educational idea, educational content and teaching method, which triggering a chain reaction of high education reform; In favor of the local colleges and universities to "go out" to the neighboring countries to carry out cooperation in running schools. So as to promote the internationalization of high education in Yunnan.

\section{B. In Favor of Making Good Use of the Geographic Advantage of Yunnan Province, Training Personnel for the Countries Along "The Belt and Road"}

Yunnan Province is the most convenient place to enter the South and Southeast Asia from land. The biggest advantage is the location. Construct Yunnan high education pivot combine with the advantage of geographic, discipline construction and training of professionals of Yunnan province. Innovating the mode of training personnel and course construction system facing South and Southeast Asia. In order to implement the initiatives of "The Belt and Road" training personnel who is proficient in Chinese and related foreign language, familiar with international competition rules and having a global vision in the country along the Belt and Road, attracting more students to study and communicate in Yunnan, promoting people-to-people bonds better.

\section{In Favor of Strengthening Education and Culture Exchanges, Communication and Regional Cooperation with Neighbor Countries}

The construction of Yunnan high education pivot will help promote the culture exchanges with neighbor countries, strengthen the communication with education academic institutions, think tanks, enterprise and civil in neighbor countries, promote the communication with culture, education, health, science and technology, tourism and other fields of neighbor countries actively to create a integration area of cultures, to carry out civil diplomacy, to promote people-topeople bonds.

\section{COUNTERMEASURE OF ESTABLISHING YUNNAN High EDUCATION RADIATION CENTER}

General Secretary Xi Jinping proposed the radiation center facing South and Southeast Asia, gave a new meaning of it by borrowing the concept of traditional radiation. The core is openness, cooperation and development. The purpose is promoting internal and external linkage, mutual benefit and common development. Yunnan province construct the pivot facing South and Southeast Asia is in order to making good use of the geographic advantage, bringing together a wide range of domestic and foreign resources, with the theme of open, development, cooperation and win-win, promoting the internal and external linkage and east-west opening deeply, to create regional economic center, regional integrated transport hub, international economic and trade cooperation base and regional cultural exchanges center.

The nineteenth meeting of central leading group for comprehensively deepening reforms agreed opinions on the new stage of the work of opening education on December $9^{\text {th }}$ of 2015, given the work of opening education more important significance, proposed persist to open wider, strengthen Chinese education, promoted culture exchanges, promoted Chinese quality of education, soft power and international influence. Opening education is an important part of Chinese reform and opening up, undertaking the mission of promoting the implementation of innovation-driven development strategy, education strategy and talent strategy. 
The establishment of Yunnan high education radiation, educational and cultural exchanges and personnel training base between Yunnan province and South and Southeast Asia countries, is the important part of the opening education of Yunnan province. According to the connotations of the construction of Yunnan high education pivot, specific measures and countermeasures for establishing are as follow:

\section{A. To Enhance the Level of Internationalization of High Education in Yunnan}

Internationalization is the mission requirements when high education services national strategy, International education, cultural and academic exchanges are important means of public diplomacy, the proposition of "The Belt and Road" made an urgent request of speeding the process of internationalization of high education, internationalization is also an important indicator to measure the level of running a university. Internationalization is not just a simple increase in the number of foreign students and exchange students, not just hold more international conferences, not just open more foreign language courses or set more International Day, The more important is updating philosophy, content and teaching methods of education through internationalization, causing chain reaction of high education reform. In the process of internationalization of high education in Yunnan, not only looking at the world and learning advanced international educational philosophy but also basing on local characteristics and clarifying our position, So as to eventually form our own school characteristics in line with the actual through internationalization. Facts have proved that, the development path of the introduction of foreign highquality resources-integration-localization-international is successful practice of internationalization of high education in Yunnan.

\section{B. To Innovate the Talent Cultivation Modes Facing South and Southeast Asia, Construct the Order-oriented International Talents Training Base That Service "The Belt and Road" Initiatives}

Talent cultivation mode is the sum of educational philosophy related to personnel training, classification and discipline set, curriculum and course content,teaching methods and means curriculum and teaching evaluation, etc. Training a large number of international personnel with international perspective, familiar with international rules and who is able to participate in international affairs and international competitive is the aim of proposing the long-term education reform and development plan. Talented person is the most important part of promoting "The Belt and Road" strategy, urgently need to train different kinds of talented person who are familiar with related languages and international competition rules and have international perspective. We should do researches targeted at the demand of talented person of related going out companies with "The Belt and Road" strategy, construct the scheme of order-based personnel training mode and base facing South and Southeast Asia from the facets of objectives, philosophy, curriculum, teaching methods, teaching staff of personnel training.

\section{To Develop Talent Cultivation Modes and Curriculums for Attracting Overseas Students of the Countries and Areas Along "The Belt and Road", to Establish Talent Training Base which Services the Talent Demands of the Countries and Areas Along "The Belt and Road"}

"The Belt and Road" initiative involves 66 countries and regions, countries along "The Belt and Road" also urgently needs talented person who are proficient in Chinese and familiar with Chinese economic and cultural strategy. Through deeply research and analysis of characteristics of culture and education and personnel training mode as well as the talent demand characteristics complex with "The Belt and Road" initiative of the countries along "The Belt and Road", in order to adjust and reform personnel training mode and construction of curriculum of Yunnan high education, to attract more foreign students to study and exchange in Yunnan universities, service the demand of talented person of the countries along "The Belt and Road" better.

\section{To Build Implementation Path of Yunnan Local Universities to "go out" to Carry Out Overseas Education and Radiate Surrounding Countries and Mode Selection}

To study in China and "going out" to run a school is an important initiative to train international talented person of countries along "The Belt and Road", according to the data of education ministry, China has four overseas educational institutions and 98 overseas education projects currently. To do deep research and analysis of embodiment mode of four overseas education institutions and 98 overseas education projects, to study the difficulties and issues of Yunnan local universities "go out" to carry out overseas education. Compared with the successful out-put models that developed countries had in the process of internationalization of high education, analysis the diversity feature of high education of the countries along "The Belt and Road", study the running strategy of local universities to "go out", which is implementation steps and patterns when we carry out overseas education in the countries along "The Belt and Road", including the standards and specifications of foreign institutions mode selection, international course setting, selection and training of teachers, training program and implementation plan, degree-granting and academic norms, student registration and management, quality evaluation system, finance and asset management, etc. While to explore and refine the related theories of high education going out to overseas.

\section{ACKNOWLEDGMENT}

On the completion of this paper, I would like to express my deepest gratitude to my colleagues and students whose kindness and advice have made this work possible. Without their help, it would not be possible for me to complete this paper in such a short period of time. Their willingness to give me their time so generously has been much appreciated.

\section{REFERENCES}

[1] L.J. Chen, "Countermeasures and Thoughts of speeding up the construction of pivot facing South Asia and Southeast Asia," Kunming University of Technology (Social Science Edition), vol. 6, 2015, pp. 1724. 
[2] L.J. Chen, "Connotations and suggestions for the construction of pivot in Yunnan," Yunnan Social Sciences, vol. 6, 2015, pp. 1-6.

[3] Newspaper commentator, "Break a path by leaps and bounds - On earnestly study and implement General Secretary Xi Jinping visits Yunnan important speech," Yunnan Daily, 2015.

[4] J. Ren. "Construction of pivot facing South Asia and Southeast Asia," Socialist Forum, vol. 4, 2015, pp. 32-33.
[5] H.X. Sun, and J. Fu, "The impact of Chinese Literature radiate on Korean Literature from the perspective angle - "Fairy Cave"," red fairy bag as the center, Changchun University, vol. 7, 2014, pp. 921--923.

[6] Z.P. Yin, "Boost for construction of pivot facing South Asia," Southeast Asia, Yunnan Daily, 2015.

[7] M. Zhong, "Speeding up the construction of pivot facing South Asia and Southeast Asia," Yunnan Daily, vol. 25, 2015. 